\title{
Salivary Cariogenic Microflora, Buffer Capacity, Secretion Rate and Its Relation to Caries Experience in 12 to 15 Years Old Indian Schoolchildren
}

\author{
${ }^{1}$ Nithin Manchery Gopinath, ${ }^{2}$ Joseph John
}

\begin{abstract}
Background: Dental caries is a disease of multifactorial etiology and its prevalence is more in developing countries, including India. It was of interest to study the caries risk factors, mainly salivary parameters and its cariogenic association.
\end{abstract}

Materials and methods: Clinical examination of 108 children was done for dental caries. Stimulated saliva was collected and salivary flow rate, salivary buffering capacity; Streptococcus mutans and Lactobacillus counts were assessed. Differences between mean decayed, missing and filled teeth (DMFT) and salivary risk factors and their relation were assessed.

Results: The mean DMFT was 2.41. Statistically, highly significant relation was found between Streptococcus mutans $\left(\chi^{2}=\right.$ 43.34, $p<0.000)$ and DMFT categories. Similar results were also obtained for Lactobacillus $\left(\chi^{2}=25.95, p<0.000\right)$. Similarly, the role of salivary $\mathrm{pH}$ and secretory rate was also found to be significant in contributing to caries risk.

Conclusion: The results of current study showed that there exist's a strong association either directly or indirectly between salivary variables, like salivary microflora, buffer capacity and secretion rate to caries experience.

Keywords: Salivary buffering, Lactobacilli, Mutans count, Caries experience, India.

How to cite this article: Gopinath NM, John J. Salivary Cariogenic Microflora, Buffer Capacity, Secretion Rate and Its Relation to Caries Experience in 12 to 15 Years Old Indian Schoolchildren. J Contemp Dent 2015;5(1):12-16.

Source of support: Nil

Conflict of interest: None

\section{INTRODUCTION}

Dental caries is the most prevalent dental disease affecting the human race. It has been one of the major oral health problems in industrialized and increasing

\footnotetext{
${ }^{1}$ Senior Lecturer, ${ }^{2}$ Professor and Head

${ }^{1}$ Department of Public Health Dentistry, Madha Dental College Chennai, Tamil Nadu, India

${ }^{2}$ Department of Public Health Dentistry, Saveetha Dental College, Chennai, Tamil Nadu, India

Corresponding Author: Nithin Manchery Gopinath, Senior Lecturer, Department of Public Health Dentistry, Madha Dental College, Chennai, Tamil Nadu, India, Phone: 04426272077 e-mail: dr.nithinmg@gmail.com
}

in developing countries, and it affects 60 to $90 \%$ of schoolgoing children and adults. ${ }^{1}$ The etiology and pathogenesis of dental caries are known to be multifactorial. ${ }^{2-6}$

It is generally accepted that saliva secretion and salivary components secreted in saliva are important for dental health. Saliva is vital for the integrity of the teeth as well as soft tissues. ${ }^{7}$ Probably the most important caries-preventive functions of saliva are the flushing and neutralizing effects. ${ }^{4}$

The secretion rate and quality of saliva are important not only in caries development but also for remineralization. ${ }^{7}$ Reduced salivary flow rate and the concomitant reduction of oral defense systems may cause severe caries and mucosal inflammations. ${ }^{4}$ Thus, the possible reasons for change in oral balance that favors the process of demineralization leading to caries may be answered by measuring important salivary parameters.

Bacteria also play an integral role in the carious process. Cariogenic microorganisms colonize on tooth surfaces, cause a marked reduction of $\mathrm{pH}$ in the presence of a sugar substrate, and consequently induce dental caries. $^{8}$ There are several microorganisms which have been characterized as having high cariogenic potential, but two classes of microorganisms, Streptococcus mutans and lactobacilli have been extensively studied.

The studies have shown that the subjects with active caries tend to harbor a higher number of mutans streptococci and lactobacilli in their saliva and plaque than those who are caries free. Moreover longitudinal studies have demonstrated that there is increase overtime in the number of $S$. mutans and lactobacilli associated with the onset and progression of caries. ${ }^{9-13}$ Researches investigating the caries predictive value of mutans streptococci and lactobacilli counts in children have also shown that lactobacilli are rarely found alone and are often isolated together with mutans streptococci in plaque and saliva. ${ }^{14-16}$

In India, children comprise $40 \%$ of a rapidly growing population. The prevalence of dental caries varies from 33.7 to $90 \%$ in children and is increasing at an alarming rate. ${ }^{17,18} \mathrm{~A}$ variety of potential predictors have been examined for an association with caries increments in various cross-sectional and longitudinal studies. 
Many attempts have been made to identify those children who are more susceptible to caries development so as to implement specific prevention programs for them. The dental caries prevalence among the children in this region has been reported earlier but the risk profile of dental caries in these children has not been investigated much.

Thus, the present study was undertaken with the aim to evaluate any possible relationship among salivary cariogenic flora, buffer capacity, secretion rate and caries experience among 12 to 15 years old schoolchildren in India and also to establish whether there is any possible relationship between salivary parameters and caries experience.

\section{MATERIALS AND METHODS}

This is a part of a cross-sectional study which was conducted in the assessment of caries risk in schoolchildren of 12 to 15 years old of Chennai city, which is located in the state of Tamil Nadu, southern part of India.

List of schools in Chennai was obtained. Schools in Chennai were divided into four zones based on the geographical location as north, south, central and east. One zone was selected at random, from which a school was selected. Based on the inclusion criteria, those children with good physical health and free of any systemic illness were considered for the study.

Sample size required for the study was calculated to be $\mathrm{N}=108$, with $80 \%$ power at $5 \% \alpha$-error, based on the previous studies. An approval from the concerned school authorities and written informed consent from the parents and children were obtained. Prior to the start of the study ethical approval was obtained from the Institutional Review Board, Saveetha University. The study was carried out using a self designed, pretested proforma which consisted of two parts. The first part collected the demographic details of the children and the second consisted of clinical examination and saliva collection.

The oral examination of schoolchildren was carried out under natural light using a plane mouth mirror, and WHO probe. Oral examination was carried out by a single examiner who had been trained through a series of clinical training sessions for recording the index at the department of Public Health Dentistry at Saveetha Dental College and Hospital, Chennai. The sterilization of instruments was done by autoclaving. No radiographs were used. Caries status was determined by using WHO (1997) Dentition Status and Treatment Needs.

After examination, saliva sampling was performed for each child. The sampling was performed in the school in groups of four to six children. Children were made to sit comfortably on the chair and asked to swallow the preexisting saliva, in order to clear the mouth for any residual unstimulated saliva. After this each student was asked to chew a standard piece of paraffin wax, for 5 minutes and the stimulated saliva was collected. The saliva samples of all the participants were identified by a code number during the period of sample collection and processing.

Salivary flow rate: Once the participant could chew comfortably on the wax, he or she was asked to expectorate all saliva formed over a 5-minute period, into the graduated sterile cylinder. After disappearance of the salivary froth, the secretion rate was estimated in milliliters per minute.

Salivary buffering capacity: $0.5 \mathrm{ml}$ of saliva was added to $1.5 \mathrm{ml}$ of 0.005 molarity of hydrochloric acid (HCL). Buffering capacity of saliva was determined by assessing the change in $\mathrm{pH}$ using commercially available indikrom paper, which have a predetermined $\mathrm{pH}$ range and categorized accordingly.

Microbial assessment: By means of a sterile disposable syringe, $0.5 \mathrm{ml}$ aliquot of saliva collected directly from the oral cavity was injected in a previously labelled sterile bottle containing $2 \mathrm{ml}$ of transport medium. The samples were processed on the same day in the Department of Microbiology, Saveetha Dental College.

Laboratory procedure: The samples were vortexed to uniformly mix the saliva and the media using a cyclomixer. Using an inoculation loop (standard loop with $4 \mathrm{~mm}$ inner diameter) $10 \mathrm{ml}$ of the vortexed sample was streaked on mitis salivarius agar selective for $S$. mutans and on Rogosa SL agar for Lactobacillus. The mitis salivarius agar plates were incubated in an anaerobic jar for 48 hours at $37^{\circ} \mathrm{C}$ in an incubator and similar procedure were followed for Rogosa SL agar plates, which were incubated for 96 hours. The colony characteristics and the number of colony forming units of S. mutans (CFU/ $\mathrm{ml}$ ) and Lactobacillus (CFU/ml) of saliva was determined using a colony counter.

The data collected were analyzed and tested for significance using statistical software packages, SPSS software for windows (version 17.0). ANOVA was done to estimate differences between means. Independent t-test, Chi-square test for association and Spearman correlation was done to explore correlation between dental caries experience and salivary factors.

\section{RESULTS}

The total numbers of study participants were 108, of which 56 were males and 52 females. Table 1 shows the distribution of study subjects according to mean DMFT and DMFS. The mean DMFT was found to be higher in 
boys when compared to the girls and the difference in caries experience between the genders was found to be significant statistically.

A total of $91.66 \%$ study subjects carried detectable salivary levels of $S$. mutans while lactobacilli was found in $85.19 \%$ of the study subjects. The secretion rate was estimated between 0.4 and $1.5 \mathrm{ml} / \mathrm{min}$ in the examined subjects with a mean flow rate of $0.27 \pm 0.485 \mathrm{ml} / \mathrm{min}$. Majority of study subjects presented with a salivary flow rate score of $0(>0.7 \mathrm{ml} / \mathrm{min})$ and with a buffer capacity of $>6 \mathrm{pH}$.

Table 2 shows the distribution of study subjects according to salivary mutans count and caries experience. It was seen that caries experience was directly related to mutans count. The difference was found to be highly significant statistically on Chi-square test.

Table 3 represents the results of individual salivary factors to corresponding mean DMFT and DMFS value.

In the present study, $37.9 \%$ of the children had a score of $1\left(10^{4} \mathrm{CFU} / \mathrm{ml}\right)$ and $44.9 \%$ had a score of 2 $\left(10^{5} \mathrm{CFU} / \mathrm{ml}\right)$. The diet contents showed a significant association to caries experience (ANOVA, $\mathrm{p}<0.000$ ). The mutans streptococci estimations were directly related to the DMFT and DMFS scores of the children and were found to be statistically significant. Regarding salivary secretory rate, there were significant differences among the different categories of saliva secretion rate (ANOVA, $\mathrm{p}<0.001)$. Children with normal salivary secretion rate developed fewer new carious lesions than the other groups. A significant difference was also seen between mean DMFT and DMFS scores and salivary buffering capacity (ANOVA, $\mathrm{p}<0.002$ ).

Table 4 shows the correlation between salivary variables and caries experience. All the variables showed a highly significant correlation with the DMFT and DMFS values.

Table 1: Distribution of study subjects according to mean DMFT and DMFS scores

\begin{tabular}{llll}
\hline Gender $^{*}$ & $N$ & $D^{*}$ MFT $^{*}($ mean $\pm S D)$ & DMFS $($ mean $\pm S D)$ \\
\hline Boys & 56 & $2.46 \pm 1.47$ & $4.14 \pm 2.21$ \\
Girls & 52 & $1.88 \pm 1.02$ & $3.33 \pm 2.18$ \\
\hline Total & 108 & $2.19 \pm 1.30$ & $3.75 \pm 2.22$ \\
\hline
\end{tabular}

${ }^{*} \mathrm{t}=2.355 ; \mathrm{df}=107 ; \mathrm{p}<0.023$

\section{DISCUSSION}

Dental caries is a multifactorial disease with several wellknown components teaming up in the disease process. The results of the present study showed that, out of the 108 schoolchildren, 98 (90.7\%) children presented with caries of which 52 (53.06\%) were boys and 46 (46.93\%) were girls. A statistically significant difference was observed in the mean DMFT between males and females. This observation was in contrast to studies carried out by Hegde et al ${ }^{17}$ in Belgaum and Zickert et $\mathrm{al}^{19}$ at Sweden where no association was found between DMFT and gender.

The mean DMFT recorded was 2.19. This mean DMFT was found to be lesser than in the study conducted by Hegde et $\mathrm{al}^{17}$ (2.43). It was far higher than (1.18) in the study conducted by Kulkarni and Deshpande ${ }^{20}$ where the mean DMFT was 1.18. The possible difference in DMFT could be also due to the difference in population studied and where the studies had been conducted. The percentage of children caries free in the current study was only $9.2 \%$.

A lot of research has been done to find out and prove the influence of salivary MS on caries experience in children. Our results also showed that the caries experience was directly related to salivary $S$. mutans level. This type of positive relation has been reported in earlier studies of such kind. ${ }^{18,19,22-27}$

Lactobacilli are notable organisms in dental caries and clinical studies have shown positive correlation of Lactobacilli number in the dental plaque and saliva of caries active individuals. ${ }^{19}$ Most of the children in the present study had a Lactobacillus score of 2 (44.44\%) and this difference was found to be statistically significant. This high score could be possible that a majority of the subjects in the present study were presented with carious lesions that were in advanced stages as and this can be attributed due to the type of children who participated in this study.

As it is known, saliva's pH has no influence on caries experience in different age groups. But, low salivary buffer capacity influences on the growth of salivary cariogenic microflora. The analysis of buffer capacity of saliva showed that the majority $(81.48 \%)$ of study subjects presented with a buffer capacity of $>6 \mathrm{pH}$, followed

Table 2: Distribution of study subjects according to mutans count and caries status

\begin{tabular}{|c|c|c|c|c|c|c|c|c|c|c|}
\hline \multirow{3}{*}{$\begin{array}{l}\text { DMFT } \\
\text { score }\end{array}$} & \multicolumn{8}{|c|}{ Streptococcus mutans (CFU/ml) } & \multirow{2}{*}{\multicolumn{2}{|c|}{ Total }} \\
\hline & \multicolumn{2}{|c|}{$O$ (neg) } & \multicolumn{2}{|c|}{$1\left(<10^{4}\right)$} & \multicolumn{2}{|c|}{$2\left(10^{4}-10^{5}\right)$} & \multicolumn{2}{|c|}{$3\left(>10^{5}\right)$} & & \\
\hline & $n$ & $\%$ & $n$ & $\%$ & $n$ & $\%$ & $n$ & $\%$ & $n$ & $\%$ \\
\hline 0 & 3 & 30 & 7 & 70 & 0 & 0 & 0 & 0 & 10 & 9.2 \\
\hline$<3$ & 6 & 10.7 & 7 & 12.5 & 23 & 41 & 20 & 35.7 & 56 & 51.8 \\
\hline$>3$ & 0 & 0 & 2 & 4.7 & 18 & 42.8 & 22 & 48.8 & 42 & 38.9 \\
\hline Total & 9 & 8.3 & 16 & 14.8 & 41 & 37.9 & 42 & 38.9 & 108 & 100 \\
\hline
\end{tabular}

$\chi^{2}=43.34 ; \mathrm{df}=6 ; p<0.000$ 
Table 3: Distribution of study subjects with mean DMFT/DMFS scores according to salivary variables

\begin{tabular}{|c|c|c|c|c|}
\hline Salivary variables & & $N$ & Mean DMFT & Mean DMFS \\
\hline \multicolumn{5}{|c|}{ Salivary Lactobacillus (CFU/ml) of saliva } \\
\hline 0 & Very low $\leq 10^{3} \mathrm{CFU} / \mathrm{ml}$ & 16 & $1.00 \pm 0.81$ & $1.81 \pm 1.42$ \\
\hline 1 & Low, $10^{4} \mathrm{CFU} / \mathrm{ml}$ & 41 & $2.17 \pm 1.24$ & $4.02 \pm 2.51$ \\
\hline 2 & Moderate, $10^{5} \mathrm{CFU} / \mathrm{ml}$ & 48 & $2.50 \pm 1.25$ & $4.00 \pm 1.79$ \\
\hline 3 & High, $\geq 10^{6} \mathrm{CFU} / \mathrm{ml}$ & 3 & $3.67 \pm 1.15$ & $6.00 \pm 2.64$ \\
\hline ANOVA p-value & & & 0.000 & 0.001 \\
\hline \multicolumn{5}{|c|}{ Salivary mutans streptococci (CFU/ml) of saliva } \\
\hline 0 & Negligible & 9 & $1.00 \pm 0.86$ & $1.67 \pm 1.50$ \\
\hline 1 & $<10^{4} \mathrm{CFU} / \mathrm{ml}$ & 16 & $1.31 \pm 1.53$ & $1.94 \pm 2.17$ \\
\hline 2 & $10^{4}-10^{5} \mathrm{CFU} / \mathrm{ml}$ & 41 & $2.46 \pm 1.22$ & $4.46 \pm 2.11$ \\
\hline 3 & $>10^{5} \mathrm{CFU} / \mathrm{ml}$ & 42 & $2.50 \pm 1.08$ & $4.19 \pm 1.86$ \\
\hline ANOVA p-value & & & 0.000 & 0.000 \\
\hline \multicolumn{5}{|c|}{ Salivary secretion amount (stimulated saliva test) } \\
\hline 0 & $0.7 \mathrm{ml} / \mathrm{min}$ & 81 & $1.84 \pm 1.12$ & $3.46 \pm 2.23$ \\
\hline 1 & $0.3-0.7 \mathrm{ml} / \mathrm{min}$ & 25 & $3.00 \pm 1.04$ & $4.40 \pm 1.82$ \\
\hline 2 & $<0.3 \mathrm{ml} / \mathrm{min}$ & 2 & $6.00 \pm 0.00$ & $7.50 \pm 2.12$ \\
\hline ANOVA p-value & & & 0.001 & 0.009 \\
\hline \multicolumn{5}{|c|}{ Salivary buffering capacity $(p H)$} \\
\hline 0 & $\mathrm{pH}>6.0$ & 88 & $1.99 \pm 1.22$ & $3.40 \pm 2.03$ \\
\hline 1 & $\mathrm{pH} 4.5-5.5$ & 16 & $2.88 \pm 1.25$ & $4.88 \pm 2.52$ \\
\hline 2 & $\mathrm{pH}<4.0$ & 4 & $3.75 \pm 1.50$ & $7.00 \pm 0.81$ \\
\hline ANOVA p-value & & & 0.002 & 0.000 \\
\hline
\end{tabular}

Table 4: Correlation between salivary variables and caries experience

\begin{tabular}{lll}
\hline Variable & $D M F T$ & $D M F S$ \\
\hline Salivary lactobacilli & $0.366^{\mathrm{a}}$ & $0.289^{\mathrm{a}}$ \\
Salivary S. mutans level & $0.363^{\mathrm{a}}$ & $0.338^{\mathrm{a}}$ \\
Salivary secretory rate & $0.432^{\mathrm{a}}$ & $0.245^{\mathrm{b}}$ \\
Salivary buffering capacity & $0.332^{\mathrm{a}}$ & $0.328^{\mathrm{a}}$ \\
\hline${ }^{\mathrm{a} C o r r e l a t i o n}$ is significant at the & 0.01 level; $^{\mathrm{b}}$ Correlation is \\
significant at the 0.05 level &
\end{tabular}

by $14.81 \%$ with a $\mathrm{pH}$ of 4.5 to 5.5 . In the present study, secretion rate was estimated between 0.3 and $1.5 \mathrm{ml} / \mathrm{min}$ for the overall subjects with a mean flow rate of $0.27 \pm$ $0.485 \mathrm{ml} / \mathrm{min}$. A significant correlation was seen between the mean caries score and the salivary buffer capacity and flow rate. This result was in to contrast to the studies conducted previously by Sullivan et $\mathrm{al}^{28}$ and Russell JI et $\mathrm{al}^{29}$ which showed no significant difference between the salivary $\mathrm{pH}$ and salivary flow rate and the mean caries score.

Comparison of all results with other studies was not possible, as disparity between results exists. This could be attributed to the differences in DMFT values, dietary patterns, oral hygiene practices, genetic factors, and several other factors peculiar to the study population. Also, distinct technique of saliva sampling and cultivation of bacteria can contribute to variation.

One issue which requires to be considered is the use of cross-sectional study design which has been used also in the present study as well as by other authors to document the correlation between microorganisms and dental caries. In such a kind of study, a single saliva/ plaque sample is taken to record the count of microorganisms, which probably indicates the microbial count at a certain point of time, since dental caries develops over a considerable period of time, during which bacterial count would perhaps fluctuate in response to the changing oral environment.

Tukia-Kulmala and Tenovuo have reported that intraindividual variation in salivary factors and microorganisms does exist with respect to time and that single point measurement of salivary factors and microorganisms are unreliable for caries-diagnostic or predictive purposes. ${ }^{22,29}$ Also, Kristila et al ${ }^{30}$ considered longitudinal analysis to be the only way to determine the existence of any saliva-caries relationships with clinical significance, since cross-sectional data do not necessarily reflect the oral situation at the time when the disease process has started.

Therefore, it is suggested that further longitudinal study designs be undertaken wherein microbial samples are taken at regular intervals which would in turn help in studying the variation in the count of the microorganisms as well as the important factor time in the Keyes circle of dental caries formation.

To conclude, the results of current study showed that, there exists a strong association either directly or indirectly between salivary variables, like salivary microflora, buffer capacity and secretion rate to caries experience. 
The data thus obtained can be used as a baseline to plan a preventive program for prevention of caries in the schoolchildren of this region.

\section{REFERENCES}

1. Petersen PE, BourgeoisD, OgawaH, Estupinan-DayS, NdiayeC. The global burden of oral diseases and risks to oral health. Bull World Health Organ 2005;83(9):661-669.

2. Beck JD, Kohout F, Hunt RJ. Identification of high caries risk adult: attitude, social factors and diseases. Int Dent J 1988; 38(4):231-280.

3. Reich E, Lussi A, Newbrun E. Caries risk assessment. Int Dent J 1999;49(1):15-26.

4. Lenander-Lumikari M, Loimaranta V. Saliva and dental caries. Advanced Dent Res 2000;14:40-47.

5. Leone CW, Oppenheim GG. Physical and chemical aspects of saliva as indicators of risk for dental caries in human. J Dent Education 2001;65(10):1054-1064.

6. Hicks J, Garcia-Godoy F, Flaitz C. Biological factors in dental caries: role of saliva and dental plaque in the dynamic process of demineralization and remineralization (part I). J Clinical Pediat Dent 200;28(1):47-52.

7. Gopinath VK, Arzreanne AR. Saliva as a diagnostic tool for assessment of dental caries. Archives of Orofac Sci 2006; 1(1):57.

8. Ravindran S, Chaudhary M, Gawande M. Enumeration of salivary streptococci and lactobacilli in children with differing caries experiences in a rural indian population. ISRN Plastic Surg 2012;2013.

9. Bader JD, Graves RC, Disney JA, Bohannan HM, Stamm JW, Abernathy JR, et al. Identifying children who will experience high caries increments. Community Dentist Oral Epidemiol 1986;14(4):198-201.

10. Leverett DH, Featherstone JD, Proskin HM, Adair SM, Eisenberg AD, Mundorff SA, et al. Caries risk assessment by a cross-sectional discrimination model. J Dent Res 1993;72(2): 529-537.

11. Raitio M, Pienihakkinen K, Scheinin A. Assessment of single risk indicators to caries increment in adolescents. Acta Odontol Scand 1996;54(2):113-117.

12. Alaluusua S, Kleemola-Kujala E, Nystrom M, Evalahti M, Gronroos L. Caries in primary teeth and salivary streptococcus mutans and lactobacillus levels as indicators of caries in permanent teeth. Pediat Dentist 1987;9(2):126-130.

13. Vanobbergen J, Martens L, Lesaffre E, Bogaerts K, Declerck D. Assessing risk indicators for dental caries in the primary dentition. Community Dentist Oral Epidemiol 2001;29(6):424-434.

14. Alaluusua S, Myllarniemi S, Kallio M. Streptococcus mutans infection level and caries in a group of 5-year-old children. Caries Res 1989;23(3):190-194.

15. Babaahmady KG, Challacombe SJ, Marsh PD, Newman HN. Ecological study of Streptococcus mutans, streptococcus sobrinus and lactobacillus spp. at sub-sites from approximal dental plaque from children. Caries Res 1998;32(1):51-58.

16. Zoitopoulos L, Brailsford SR, Gelbier S, Ludford RW, Marchant SH, Beighton D. Dental caries and caries-associated microorganisms in the saliva and plaque of 3-and 4-year-old Afro-Caribbean and Caucasian children in south London. Arch Oral Biol 1996;41(11):1011-1018.

17. Hegde PP, Ashok Kumar BR, Ankola VA. Dental caries experience and salivary levels of streptococcus mutans and lactobacilli in 13 to 15 years old children of Belgaum city, Karnataka. J Indian Society of Pedodont Prevent Dentist 2005;23:23-26.

18. Purohit VD, Damle SG. Salivary counts of streptococci, lactobacilli, flow rate and buffering capacity in caries free and caries active children. J Indian Society of Pedodont Prevent Dentist 1996;14:97-106.

19. Zickert I, Emilson CG, Krasse B. Streptococcus mutans, lactobacilli and dental health in 13 to 14 years old swedish children. Community Dentist Oral Epidemiol 1982;10(2):77-81.

20. Kulkarni SS, Deshpande SD. Caries prevalence and treatment needs in 11 to 15 years old children of Belgaum city. J Indian Society Pedodont Prevent Dentist 2002;20(1):12-15.

21. Kohler B, Bjarnason S, Finnbogason SY, Holbrook WP. Mutans streptococci, Lactobacilli and caries experience in 12-year-old icelandic urban children, 1984 and 1991. Community Dentist Oral Epidemiol 1995;23(2):65-68.

22. Seppa L, Pollanen L, Hausen H. Streptococcus mutans counts obtained by a dip slide method in relation to caries frequency, sucrose intake and flow rate of saliva. Caries Res 1988;22(4):226-229.

23. Llena-Puy MC, Montanana-Llorens C, Forner-Navarro L. Cariogenic oral flora and its relation to dental caries. ASDC J Dent Child 2000;67(1):42-46.

24. Bratthall D, Serinirach R, Carlsson P, Lekfuangfu S. Streptococcus mutans and dental caries in urban and rural schoolchildren in Thailand. Community Dentist Oral Epidemiol 1986;14(5):214-216.

25. Russel JL, MacFarlane TW, Aitchison TC, Stephen KW, Burchell CK. Caries prevalence and microbiological and salivary caries activity tests in scottish adolescents. Community Dentist Oral Epidemiol 1990;18(3):120-125.

26. Weissenbach M, Chau N, Benamghar L, Lion C, Schwartz F, Vadot J. Oral health in adolescents from a small French town. Community Dentist Oral Epidemiol 1995;23(3):147-154.

27. Teanpaisan R, Kintarak S, Chuncharoen C, Akkayanont P. Mutans streptococci and dental caries in schoolchildren in Southern Thailand. Community Dentist Oral Epidemiol 1995;23(5):317-318.

28. Sullivan A. Correlation between caries incidence and secretion rate/buffer capacity of stimulated whole saliva in 5-7-year-old children matched for lactobacillus count and gingival state. Sweden Dent J 1990;14(3):131-135.

29. Tukia-kulmala $\mathrm{H}$, Tenovuo J. Intra and inter-individual variation in salivary flow rate, buffer effect, Lactobacilli, and mutans streptococci among 11 to 12-year old schoolchildren. Acta Odontol Scand 1993;51(1):31-37.

30. Kirstilla V, Hakkinen P, Jentsch H, Vilja P. 1 Tenovuo. Longitudinal analysis of the association of human salivary antimicrobial agents with caries increment and cariogenic microorganisms: a 2 year cohort study. J Dent Res 1998;77(1): 73-80. 